\title{
Mesenchymal Stem Cells from Different Tissues: Immune Status and Activity
}

\author{
Trivanović $\mathrm{D}^{*}$, Krstić $\mathrm{J}^{1}$, Mojsilović $\mathrm{S}^{1}$, Djordjević $\mathrm{IO}^{1}$, Ilić $\mathrm{V}^{2}$, Kukolj $\mathrm{T}^{1}$, Obradović $\mathrm{H}^{1}$, Jauković $\mathrm{A}^{1}$, \\ Santibanez $\mathrm{JF}^{1}$ and Bugarski $\mathrm{D}^{1}$
}

${ }^{1}$ Laboratory for Experimental Hematology and Stem Cells, Institute for Medical Research, University of Belgrade, Belgrade, Serbia

${ }^{2}$ Laboratory for Immunology, Institute for Medical Research, University of Belgrade, Belgrade, Serbia

${ }^{*}$ Corresponding author: Trivanović D, Laboratory for Experimental Hematology and Stem Cells, Institute for Medical Research, University of Belgrade, Belgrade, Serbia, E-mail: drenka.trivanovic@imi.bg.ac.rs

Citation: Trivanović D, Krstić J, Mojsilović S, Djordjević IO, Ilić V, et al. (2016) Mesenchymal Stem Cells from Different Tissues: Immune Status and Activity. J Immunol Infect Dis 3(1): 102

Received Date: December 30, 2015 Accepted Date: April 26, 2016 Published Date: April 27, 2016

\begin{abstract}
Mesenchymal stem cells (MSCs) have been found in almost all tissues and due to their regenerative properties represent promising tools in cell-based therapy. Role of MSCs in tissue repair is strongly governed by their interplay with immune cells and regulating factors. In addition to the first and most investigated MSCs isolated from bone marrow (BM-MSCs), other tissues were also reported as abundant sources of MSCs, such as peripheral and menstrual blood, fetal and perinatal tissues, adipose and dental tissue. Although BM-MSCs have been shown to be immunosuppressive in both in vitro and in vivo conditions, multiple evidences indicate that these cells have immunogenic properties, making their immune privileged status at least questionable. Besides their similarity with BMMSCs, MSCs isolated from alternative sources manifest significant differences in their phenotype, functionality, immune status and activity. Complexity of interactions of BM-MSCs with the immune system is also found for MSCs isolated from other tissues. Due to specific conditions present in different tissues, variability in the immune repertoire of resident MSCs is to be expected and must be taken into consideration during experimental or clinical protocol planning.
\end{abstract}

Keywords: Mesenchymal stem cells; Immunomodulatory; Bone marrow; Inflammation

\section{Introduction}

As tissue-derived stem cells, mesenchymal stem/stromal cells (MSCs) have been found in almost all vascularized tissues where they are engaged in long term maintenance of tissue homeostasis and repair [1]. Until recently, the concept of MSCs as defined by The International Society for Cellular Therapy (ISCT) [2], enabled classification of stem cells derived from various tissues, such as bone marrow, umbilical cord, adipose tissue, skin, dental tissues, peripheral blood, muscle, and amnion etc., based on their immunophenotype and trilineage differentiation potential. Recent analyses pointed out that use of MSCs in preclinical and clinical approaches failed to keep pace with established clinical applications of hematopoietic stem cells (HSCs). This raised concerns about the necessity to further standardize validation assays and compare MSCs obtained in different laboratories [3]. Although MSCs isolated from various tissues meet the same proposed criteria of ISCT (Table 1), it is questionable whether all types of tissue-derived MSCs possess similar paracrine (immunomodulatory, trophic and chemoattractant) activities, which signed them as Medicinal Signaling Cells [4]. Finally, the authors of the aforementioned criteria for MSCs characterization have suggested their extension, marking the importance of immune activity and paracrine effects of MSCs [5-7].

Although MSCs have been labeled as immunosuppressive both in vitro [8,9] and in vivo [10,12], some reports suggest that these cells can possess immunogenic properties as well $[13,14]$. Due to their importance in tissue repair, process associated with local or systemic inflammatory microenvironment, it is highly important to understand interactions between MSCs and immune system before their potential application in regenerative medicine [15]. MSCs sense stimuli in their microenvironment, which can govern their differentiation fate, as well as their immunomodulatory properties [16]. Moreover, in order to find the most suitable source of MSCs with desired properties, many authors reported immunomodulatory activities of MSCs isolated from various tissues, indicating possible mechanisms of action (Table 2). Also, many studies compared the immunomodulatory capacity of various MSCs (Table 3). As has been observed by Pevsner-Fisher [17], inter-population heterogeneity of MSCs isolated from various donors and tissues, is the main reason for great variability in experimental results. Heterogeneity in observed data might result from different nature of isolated MSCs from various tissues, examined mechanism of activity which could be predetermined for certain type of MSCs, experimental design etc. Because of the high importance of MSCs immune status in their potential clinical application, the inconsistent results require additional extensive review [18]. Here, we aim to give an overview of recent data about 
immunomodulatory capacity of MSCs, and justifiably speculate that tissue origin and specific microenvironment adjust the immune status and activity of MSCs in vitro and in vivo.

\begin{tabular}{|c|c|c|c|}
\hline Tissue-origin & Positive markers & Negative markers & Source \\
\hline Bone marrow & $\begin{array}{c}\text { CD90, CD105, CD73, CD44, } \\
\text { CD29, HLA I,CD106 b, CD166 }\end{array}$ & $\begin{array}{c}\text { CD14, CD11b, CD19, CD31, CD34, CD45, } \\
\text { CD133, HLA II, CD144, CD80, CD62L, CXCR4 }\end{array}$ & $\begin{array}{c}\text { Kern et al., Barcia et al, Yanez } \\
\text { et al }\end{array}$ \\
\hline Adipose tissue & $\begin{array}{c}\text { CD90, CD105, CD73, CD44, } \\
\text { CD29, HLA I,CD106 b, CD166 }\end{array}$ & $\begin{array}{c}\text { CD14, Cd11b, CD34, CD45, CD133, HLA II, } \\
\text { CD144, CD80, CD62L, CXCR4, CD33, CD235 }\end{array}$ & $\begin{array}{c}\text { Kern et al, Yanez et al., } \\
\text { Trivanović et al. }\end{array}$ \\
\hline Umbilical cord & $\begin{array}{c}\text { CD90, CD105, CD73, CD44, } \\
\text { CD29, CD106 }\end{array}$ & $\begin{array}{c}\text { CD11b, CD14, CD19, CD31, CD34, CD45, HLA } \\
\text { II, CD80, CD86 }\end{array}$ & $\begin{array}{c}\text { Barcia et al., Zhuang et al., Chen } \\
\text { et al., Trivanović et al. }\end{array}$ \\
\hline Umbilical cord blood & $\begin{array}{c}\text { CD90, CD105, CD73, CD44, } \\
\text { CD29, HLA I, CD106 b }\end{array}$ & $\begin{array}{c}\text { CD14, CD34, CD45, CD133, HLA II, CD144, } \\
\text { CD38 }\end{array}$ & Kern et al., Jing et al. \\
\hline Peripheral blood & $\begin{array}{c}\text { CD90, CD105, CD73, CD44, } \\
\text { CD29, CD166, CD140a }\end{array}$ & CD11b, CD45, CD34, CD19 & $\begin{array}{c}\text { Krstić et al., Trivanović et al., } \\
\text { Chong et al., Li et al. }\end{array}$ \\
\hline Menstrual blood & $\begin{array}{c}\text { CD90, CD105, CD73, CD44, } \\
\text { HLA I, CD49 }\end{array}$ & $\begin{array}{c}\text { CD14, CD34, CD45, CD31, HLA II, EPCAM, } \\
\text { CD117, CD271, CD146 }\end{array}$ & Miranda et al. \\
\hline Dental pulp & CD90, CD105, CD73, CD44 & CD11b, CD33, CD34, CD45, CD235a & Nikolić et al., Vasandan et al. \\
\hline Gingiva & $\begin{array}{c}\text { CD90, CD105, CD73, CD44, } \\
\text { CD29, CD39, HLA I }\end{array}$ & CD11b, CD14, CD34, CD45, CD31, HLA II, & Chen et al., Zhang et al. \\
\hline Periodontal ligament & $\begin{array}{c}\text { CD90, CD105, CD73, CD44, } \\
\text { CD29 }\end{array}$ & CD14, CD45, CD34, CD19, CD235, CD11b & $\begin{array}{c}\text { Vasandan et al., Okić Djordjević } \\
\text { et al. }\end{array}$ \\
\hline
\end{tabular}

Table 1: Comparison of immunophenotype of MSCs isolated from various tissues

\begin{tabular}{|c|c|c|}
\hline Tissue-origin & Mechanisms of immunomodulation & Source \\
\hline Bone marrow & $\begin{array}{c}\text { Production of IDO, PDL-1, PGE2, TGF- } \beta \text {, IL-6, IL-10, HLA-G5, HGF. Inhibition of } \\
\text { CD4+, CD8+, B cell, NK cell. Induction of Treg, CD14 CD11b+CD33+ (MDSCs), } \\
\text { tolerogenic DC }\end{array}$ & $\begin{array}{l}\text { Riberia et al., Yen et al., Cahill } \\
\text { et al. }\end{array}$ \\
\hline Adipose tissue & $\begin{array}{l}\text { Production of IDO, PDL-1, PGE2, TGF- } \beta \text {, IL-6, IL-10, HLA-G5. Inhibition of CD4+, } \\
\text { CD8+, B cell, NK cell. Induction of Treg, tolerogenic monocytes, Breg }\end{array}$ & $\begin{array}{l}\text { Riberia et al., Cro } \\
\text { Nahor et al., Gari }\end{array}$ \\
\hline Umbilical cord & $\begin{array}{l}\text { Production of PDL-1, PGE2, IL-10, HO-1, HLA-G. Inhibition of CD4+, CD8+, B cell, } \\
\text { NK cell. Induction of Treg. Inhibition of maturation of DC }\end{array}$ & $\begin{array}{l}\text { Riberia et al., Barcia et al., Castro } \\
\text { Manrezza et al., Saiedi et al. }\end{array}$ \\
\hline Umbilical cord blood & $\begin{array}{l}\text { Production of GRO chemokines, IL-10, TGF- } \beta \text {, HGF. Inhibition of proliferation of } \\
\text { lymphocytes. Induction of MDSCs. }\end{array}$ & $\begin{array}{l}\text { Chen et al., Schwaki et al., Chen } \\
\text { et al. }\end{array}$ \\
\hline Peripheral blood & $\begin{array}{l}\text { Production of IL-10, TGF- } \beta \text {. Inhibition of proliferation of lymphocytes. Decresed } \\
\text { cytotoxity of NKT and CD8+ cells. Induction of Treg. }\end{array}$ & Trivanović et al., Ljujić et al. \\
\hline Menstrual blood & $\begin{array}{l}\text { Production of IDO, PDL-1, PGE2 and TGF- } \beta \text {, IL-6, IL-10, inhibiton of generation and } \\
\text { maturation of DC }\end{array}$ & $\begin{array}{l}\text { Luz-Craford et al., Bozogmehr } \\
\text { et al. }\end{array}$ \\
\hline Dental pulp & $\begin{array}{l}\text { Production of IDO-1, TGF- } \beta \text {. Expression of Fas ligand. Inhibition of proliferation of } \\
\text { lymphocytes. Induction of apoptosis of T cells. }\end{array}$ & $\begin{array}{l}\text { Trivanović et al., Tomic et al., } \\
\text { Zhao et al. }\end{array}$ \\
\hline Gingiva & $\begin{array}{c}\text { Production of IL-10, IDO, iNOS, COX-2. Inhibition of proliferation of lymphocytes. } \\
\text { Induction of Treg }\end{array}$ & Zhang et al., Chen et al. \\
\hline Periodontal ligament & $\begin{array}{l}\text { Production of IL-10, IL-6. Expression of PDL-1. Inhibition of proliferation of lym- } \\
\text { phocytes. Induction of Treg. Suppression of activation of B cells }\end{array}$ & Liu et al., Liu et al. \\
\hline
\end{tabular}

Table 2: Immunomodulatory activities of MSCs isolated from various tissues

\section{Immunomodulatory Properties of Bone Marrow Mesenchymal Stem Cells}

Most of MSC paradigms are derived from investigation of bone marrow MSCs (BM-MSCs), first defined by Friedenstein in 1970's [19-21]. In the literature, BM-MSCs are frequently labeled as the "holy grail" cells, with desired properties: hematopoiesis support [22,23], multipotent differentiation capacity, self-renewal ability [2], and immunoregulatory potential [24]. However, it is well known that MSCs isolated from bone marrow represent a heterogenic population. Similar to HSCs, a theoretical model has provided the concept of mesenchymal cell hierarchy where MSCs lie at the top, progressing through stages of differentiation in an orderly manner to give mature cells of bone, fat, muscle and cartilage [25]. Therefore, intra-population heterogeneity of MSCs is a consequence of MSCs phenotype plasticity on the single-cell level [26] where bulk MSCs population consists of a small subpopulation of multipotent stem cells and subpopulation of bi- and uni-potent progenitors [17,27,28].

BM-MSCs occupy distinct niches in bone marrow: endosteal, stromal and perivascular niche. Because in vitro cultured pericytes share the phenotype and differentiation capacity with BM-MSCs, there are many studies which aim to elucidate relationship between them. Major question is whether BM-MSCs and pericytes are same cells which adjust their properties in response to microenvironment stimuli [16,29]. Although the origin of MSCs remains elusive, pericytes have recently emerged as likely candidates for an in vivo native counterpart of the ex vivo expanded MSCs [30]. However, since MSCs were also found in non-pericyte 
regions, their origin still remains questionable [31]. In general, MSCs are present in all vascularized organs and tissues, while their current status regarding origin, properties and function in vitro and in vivo is not well defined and is still unclear due to obvious difference between native and culture-expanded MSCs [32].

\begin{tabular}{|c|c|c|c|}
\hline MSCs & Immunomodulatory activity & Stronger effects/similarity & Source \\
\hline BM, AT, UCB & $\begin{array}{l}\text { Reduced expression of inflammatory cytokines: } \\
\text { IL-1a, IL-6, IL-8 }\end{array}$ & $\mathrm{UCB}$ & Jin et al. \\
\hline $\mathrm{BM}, \mathrm{AT}$ & Production of IDO-1, PGE2 and TGF- $\beta$ & AT & Li et al. \\
\hline BM, AT, UC, CH & Inhibition of IFN- $\gamma$ production by lymphocytes & $\mathrm{CH}$ & Yang et al. \\
\hline BM, SHEDs & Induction of Treg and inhibition of Th17 cells & SHEDs & Yamaza et al. \\
\hline $\mathrm{BM}, \mathrm{AT}, \mathrm{UCB}, \mathrm{UC}$ & $\begin{array}{l}\text { Inhibition of proliferation of lymphocytes. } \\
\text { Expression of HGF, IL-10, TGF- } \beta \text {, COX-2 }\end{array}$ & Similar effects & Yoo et al. \\
\hline UC, AT,PB, DP & $\begin{array}{l}\text { Inhibition of proliferation of lymphocytes. } \\
\text { Expression of TGF- } \beta 1, \text { COX- } 2\end{array}$ & $\begin{array}{l}\text { Similar effects. Variability in } \\
\text { gene expression }\end{array}$ & Trivanović et al. \\
\hline BM, G & Inhibition of proliferation of lymphocytes. & Similar effects & Zhang et al. \\
\hline BM, AT & Inhibition of proliferation of lymphocytes. & Similar effects & Yanez et al. \\
\hline BM, UC, UCB & $\begin{array}{l}\text { Inhibition of proliferation of lymphocytes. } \\
\text { Induction of CD4+CD25+CTLA- } 4+\end{array}$ & $\mathrm{BM}, \mathrm{UC}$ & Castro-Manrreza et al. \\
\hline BM, AT, UC & $\begin{array}{l}\text { Inhibition of } \mathrm{T} \text { cell, B cell and NK cell-mediated } \\
\text { immune response }\end{array}$ & $\begin{array}{l}\text { BM, AT regarding inhibitory } \\
\text { effects on B cells }\end{array}$ & Ribeiro et al. \\
\hline BM, Men & $\begin{array}{l}\text { Inhibition of T cell response. Production of IDO, } \\
\text { PDL-1, PGE2,TGF- } \beta\end{array}$ & $\mathrm{BM}$ & Luz-Craford et al. \\
\hline BM, DP, PDL & $\begin{array}{l}\text { Inhibition of proliferation of lymphocytes. } \\
\text { Expression of TGF- } \beta, \text { HGF, IDO- } 1\end{array}$ & $\begin{array}{l}\text { Similar effects. Variability in } \\
\text { gene expression }\end{array}$ & Wada et al. \\
\hline
\end{tabular}

BM: Bone marrow; AT: Adipose tissue; UCB: Umbilical cord blood; UC: Umbilical cord; CH: Chorion; SHEDs: Exfoliated deciduous teeth; PB: Peripheral blood; DP: Dental pulp; G: Gingiva; Men: Menstrual blood; PDL: Periodontal ligament

Table 3: Results of studies which investigated immunomodulatory capacity of various MSCs

Although heterogeneity of bulk MSCs in the context of their multipotent differentiation capacity has been described, other functional properties, such as immunodulatory properties remain to be further investigated. However, it is rational to assume that tissue microenvironment which shapes their multipotency, also manages their immune status and activity, thus giving more complexity to experimental and clinical approach, in autologous as well as in allogeneic settings [29].

\section{Immunosuppressive properties of BM-MSCs}

Many preclinical models have demonstrated that BM-MSCs can migrate to sites of inflammation and have immunomodulatory effects through direct cellular contact with immune cells or through the production of immunosuppressive soluble factors [33]. Therefore, there are number of clinical studies that use BM-MSCs to treat immune-mediated diseases, such as: Graft versus Host Disease (GVHD) [34], aplastic anemia [35], Crohn's disease [36], multiple sclerosis [37], and ischemic heart failure [38].

After establishing their immunomodulatory potential in vitro, BM-MSCs have been introduced into the clinical settings [39], in which these cells show their therapeutic effects in treatment of acute grade IV GvHD after bone marrow transplantation. It is important to mention the lack of optimization protocols considering BM-MSCs and their products including isolation, expansion and functionality, and especially for retention of their immunomodulatory potential $[40,41]$, since these efforts are crucial for safe and efficient cell-based therapy.

Recently, many cellular and molecular mechanisms involved in the interaction between BM-MSCs and various participants in the inflammation process have been highlighted. Depending on their type and intensity, inflammatory stimuli affect MSCs in a way to modulate their ability to suppress the immune response in some cases or to enhance it in others [42].

BM-MSCs express low levels of human leukocyte antigen (HLA) major histocompatibility complex (MHC) class I antigens, do not express co-stimulatory molecules (B7-1 and -2, CD40, or CD40L), and can be induced to express MHC class II antigens and Fas ligand. However, low expression of MHCII and co-stimulatory molecules indicates that direct cell contact is not the main mechanism of BM-MSCs immunomodulatory activity [40,43]. These features have often been used to explain their "immune privileged" status in allogeneic hosts. Furthermore, BM-MSCs have been shown to inhibit dendritic cell maturation [44], B cell [45] and T cell proliferation [46] and differentiation [47], impair natural killer cell activity [48], as well as support the generation of suppressive immune cells such as: regulatory T cells (Tregs) [43,49], myeloid derived suppressor cells (MDSCs) and tolerogenic dendritic cells (tDCs) [50].

Combination of many soluble factors are meritorious for immunosuppressive activity of BM-MSCs, such as: indoleamine 2,3-dioxygenase (IDO), inducible nitric oxide synthase (iNOS), cyclooxygenases (COX), metabolite prostaglandin E2 (PGE2), tumor necrosis factor $\alpha$-induced protein 6 (TSG6), transforming growth factor $\beta$ (TGF- $\beta$ ), soluble form of HLA-G5 [35,44]. Production of these factors is increased by inflammatory microenvironment stimuli, such as immune cells presence, inflammatory cytokines or activation of Toll-like receptors (TLRs) [40,51]. 


\section{Immunogenic properties of BM-MSCs}

Despite large number of data about immunosuppressive activity of BM-MSCs, there are few studies describing their immunogenic nature [52-54]. Since immunogenicity is of major concern in transplantation, clinical safety and efficacy of BM-MSCs application is therefore questioned. As described above, even though BM-MSCs have expressed low levels of MHC I molecules and lack MHC II antigens, in presence of inflammatory conditions and cytokines (interferon (IFN)- $\gamma$, tumor necrosis factor (TNF)- $\alpha$ ) in culture, expression of these MHC molecules increases [40,51,55,56]. Strong influence of microenvironment on the immune status of MSCs has been observed in an experiment using diabetic rats where allogeneic MSCs have been transplanted into tail vein or pancreas. During the later phase of transplantation, BM-MSCs which have been transplanted into pancreas develop an immunogenic phenotype, while BM-MSCs which have been transplanted into tail vein stay immunosuppressive [53]. These findings provide evidence that different microenvironment, even in one recipient, can condition opposite immune properties of BM-MSCs. Moreover, similar to all nucleated cells, BM-MSCs express MHC I molecule, and can induce allogeneic immune cell responses, as it has been demonstrated by the lysis of BM-MSCs by HLA class I mismatched memory CD8 ${ }^{+} \mathrm{T}$ cells [57]. Also, BMMSCs are also susceptible to be lysed by autologous IL-2-activated NK cells, via expression of MHC I molecule [58]. These findings suggest that despite their immunoregulatory properties, in vitro cultured BM-MSCs can be recognized as immunogenic by the immune system. Also, presence of inflammatory factors can induce expression of MHC class II in BM-MSCs, where these cells present exogenous antigens to T cells, similar as dendritic cells or macrophages [40,56]. In addition, it has been observed that BMMSCs stimulate proliferation and differentiation of naïve and memory B cells into immunoglobulin secreting plasma cells [59,60].

Moreover, it has been shown that administration of MSCs elicits innate immune attack [61] and allograft rejection in kidney transplantation [62], warning about the possibility of indirect or semi-direct allo-recognition of MSCs [33]. Taken together, these data indicate that BM-MSCs can function as immune cells. Despite inability of allogeneic BM-MSCs to be immunogenic as unmatched fibroblasts or HSCs [40,63], their immune privileged status is not uncontested anymore and it has to be reassessed, especially in the context of transplantation immunology and regenerative medicine.

\section{Transient immunomodulatory properties of BM-MSCs: MSC1 and MSC2 phenotype}

The observed changes of the immune profile of BM-MSCs, ranging from immunosuppressive to immunogenic draw attention to existence of transient immune status of these cells. Waterman et al. has explained the paradigm of pro-inflammatory MSC1 and anti-inflammatory MSC2 phenotype, similar to that in M1 and M2 macrophages. This study has showed that different TLR 2, 3 or 4 ligands shape different profiles of BM-MSCs by stimulating expression and production of immunosuppressive (IL-10) or immunogenic molecules (IL-6) [51]. As previous evidence has demonstrated that MSCs immune profile can change depending on the transplantation site and microenvironment stimuli [52,53], it is justifiable to assume the immune status of MSCs as transient $[55,56,59,64]$. In this context, it is important to acknowledge the physiological nature of MSCs whose fate is determined by their physiological setting. Considering their inherent ability to differentiate, special notice must be given to indications that MSCs immune status could be related to their differentiation state. For instance, it has been shown that osteogenic differentiation can inhibit expression of MHC II molecules in BM-MSCs, which was previously stimulated with IFN- $\gamma[65,66]$. Contrary, while BMMSCs show immunosuppressive properties in vitro, their chondrogenic differentiation has been shown to cause immunogenicity in vivo by stimulating proliferation of T cells [67]. In general, priming of MSCs with IFN- $\gamma$ is an efficient approach for stimulation of MSCs to produce immunosuppressive molecules. However, it was observed that although in vitro expanded IFN- $\gamma$-primed MSCs were immunosuppressive, their administration in vivo led to the loss of their immunosuppressive properties and finally immune rejection [64]. Taken together, it is important to consider multiple factors present during ex vivo cultivation and in vitro manipulation of BM-MSCs prior to their in vivo application, such as nutrients in media, oxygen level, growth factors or serum quality, which could interweave with the immune status of MSCs [68]. Moreover, it is possible that MSCs balance between immunosuppressive and immunogenic profile through active interplay with immune cells and regulatory factors present in native or allogeneic microenvironment. This ability of MSCs to adjust their immune profile is related to the plasticity of their immune status [69].

\section{Immunomodulatory Properties of MSCs in Peripheral Blood}

Existence of circulating MSCs has been reported when donor MSCs have been found to be engrafted in bone marrow after allogeneic transplantation of mobilized peripheral blood (PB) stem cells [70]. Previously, Wexler et al. provided data about low frequency of isolated PB-MSCs in comparison to bone marrow and umbilical cord blood [71]. The presence of a small number of MSCs has been detected in mobilized PB of healthy patients as well as those with malignancies [71,72]. Moreover, PB-MSCs have been isolated from non-mobilized peripheral blood of healthy donors and have met the criteria of ISCT [73,74]. It has been demonstrated that PB-MSCs can be mobilized to PB using granulocyte colony-stimulating factor (G-CSF), although this approach is not specific for MSCs mobilization, but for HSCs/progenitor cells or blasts [72]. It has been shown that PB-MSCs have immunosuppressing role in vivo by increasing the level of Th2 and decreasing the level of Th1 cytokines, while stimulating generation of $\mathrm{CD} 4^{+} \mathrm{FoxP} 3^{+} \mathrm{T}$ cells and producing IL-10. Thus, by impairing immune response, PB-MSCs have also been shown to promote breast tumor growth [75]. Furthermore, it has been demonstrated that osteogenic differentiation of PB-MSCs plays a crucial role in bone tissue healing [76]. While presence of circulating MSCs is to be expected in the peripheral blood of a patient, when they migrate toward sites of 
Journal of Immunology and Infectious Diseases

inflammation or injury, their presence in peripheral blood of healthy donors opens a question about their origin. However, these findings suggest that peripheral blood could be a promising source of MSCs, while their immune status and activity need to be further elucidated.

\section{Immunomodulatory Properties of MSCs in Menstrual Blood}

Regeneration of human endometrium is dependent on resident epithelial and stromal stem/progenitor cells. One of the layers of endometrium, signed as functionalis layer, is shed during menstruation and is a major part of the menstrual fluid. First evidence about stem cells in endometrium has been obtained in 2004 by Chan et al. [77], while MSCs were first isolated from endometrium 2007 by Meng et al. [78]. Menstrual blood could be available, abundant, low cost and free of ethical concerns source of MSCs (MenSCs) [79,80]. Besides their supportive role in the expansion of hematopoietic stem cells [81], it has been demonstrated that MenSCs possess lower immunosuppressive properties when compared to BM-MSCs, because they produce lower levels of IDO, PDL-1, PGE2 and TGF- $\beta 1$ [82]. However, it has been observed that MenSCs impair maturation of DC, an effect where IL-6 and IL-10 has been proposed to be involved [83]. Although MenSCs represent promising MSCs type, their immune properties and mechanisms involved in the regulation of their immunomodulatory activity have to be investigated in detail.

\section{Immunomodulatory Properties of MSCs in Fetal and Perinatal Tissues}

MSCs can be isolated from extra-embryonic tissues without ethical concerns, because these tissues are normally discarded after birth [84]. Fetal tissues are considered to be abundant source of MSCs and progenitor cells, obtained after normal pregnancy and also spontaneous abortion or stillbirth [85]. Today, MSCs has been isolated from many fetal and perinatal tissues: amniotic fluid (AF-MSCs) [86], human amnion membrane (HAM-MSCs) [87], chorion membrane (CM-MSCs), decidua (D-MSCs) [88], placenta (P-MSCs) [89], cord blood (CB-MSCs) [90], whole umbilical cord (UC-MSCs) [91] and Wharton's Jelly (WJ-MSCs) $[73,92]$. In the literature, there are many claims about the immune privileged status of MSCs derived from fetal tissues which can be transplanted into the host without immune rejection [84]. In order to establish tolerogenic fetal immune system, fetal CD4 ${ }^{+}$ $\mathrm{T}$ cells are forced to differentiate to Treg toward antigens expressed by chimeric maternal cells to promote self-tolerance in fetal tissue. Fetal cells express HLA-G for immune tolerance during pregnancy and this suggests low immunogenicity and tolerogenic state of fetal stem cells. This ability of fetal cells to provide self-tolerance is also known as layered immune system, which in adult tissue becomes more defensive [85,93].

Similar as BM-MSCs, WJ-MSCs express MHC class I (HLA-ABC) at low levels but do not express class MHC class II (HLA$\mathrm{DR}$ ) and co-stimulatory antigens such as CD80, CD86, CD40 and CD40L implicated in activation of both T and B cell response. Therefore, WJ-MSCs are considered for both autologous and allogeneic use [94]. Contrary to BM-MSCs, treatment with IFN- $\gamma$ did not induce expression of HLA-DR in WJ-MSCs, suggesting their less immunogenic nature than BM-MSCs [95]. Moreover, it has been shown that WJ-MSCs produce larger amounts of IL-10, TGF- $\beta$, heme oxygenase-1 (HO-1) and HLA-E, HLA-G and HLA-F than BM-MSCs $[84,96,97]$. However, it has been shown that exposure to IFN- $\gamma$ induce immunogenicity of transplanted WJ-MSCs, thus opening a question whether it is possible to maintain the immunosuppressive profile of WJ-MSCs upon transplantation [98].

Efficiency of WJ-MSCs and UCB-MSCs as immunosuppressive cells which inhibit proliferation of T cells has been demonstrated $[99,100]$, suggesting them as alternative to BM-MSCs. In another study, it has been observed that BM-MSCs and P-MSCs have stronger immunosuppressive capacity than WJ-MSCs, due to generation of CD $4^{+} \mathrm{CD} 25^{+} \mathrm{FoxP} 3^{+} \mathrm{T}$ cells $[101,102]$. It was also found that human P-MSCs can expand CD14-CD11b+CD33+ human MDSCs which suppress allogeneic lymphocyte proliferation and increase the number of Treg cells [103]. In addition, UCB-MSCs produce soluble factors, such as GRO chemokine's, which promote generation of MDSCs from monocyte-derived dendritic cells [50]. Interestingly, it was reported that UC-MSCs express glycocalyx matrix which contains TSG6 when they were exposed to inflammatory conditions. These UC-MSCs stimulated generation of Treg and inhibited polarization of macrophages toward pro-inflammatory M1 phenotype [104].

Taken together, fetal tissues represent a promising source of MSCs with immunomodulatory potential, although all cellular and molecular mechanisms involved need to be further investigated.

\section{Immunomodulatory Properties of MSCs in Adipose Tissue}

Adipose tissue is a well-known abundant source of MSCs, which have firstly been isolated by Zuk et al. from aspirated fat [105]. Beside abundance, a lack of ethical concerns makes these MSCs promising cells for cell-based therapy. Adipose tissue MSCs (ATMSCs) persist in stromal-vascular fraction (SVF) together with pericytes, endothelial cells, preadipocytes, hematopoietic cells and immune cells such as macrophages, NK and T cells. Besides their role in tissue homeostasis maintenance, AT-MSCs have an important role in the vascularization of adipose tissue. Also, similar to BM-MSCs, AT-MSCs are known to support hematopoiesis, specifically stimulating generation of macrophages [106]. Distinctive to circulating macrophages, population of CD34 expressing, fibroblast-like macrophages with multipotency similar to AT-MSCs have been identified in human white adipose tissue [107]. These macrophages have M1 anti-inflammatory phenotype [108]. Some reports described adipose tissue as a resident tissue for hematopoietic stem/progenitor cells committed to mast cells [109] and hemangioblasts [110]. Functional properties of AT-MSCs are especially interesting in development of obesity, which involves change of cytokine milleu in adipose tissue. It has been reported that phenotype of AT-MSCs can be altered due to obesity or weight loss-related inflammation [111]. 
The inhibitory effect of AT-MSCs on T cell proliferation has been demonstrated [9,111], and some reports have found that ATMSCs have stronger immunosuppressive effects than BM-MSCs [112]. However, Crop et al. has observed that, in the presence of lymphocytes, AT-MSCs highly express IL-6, IL-8, TNF- $\alpha$, as well as immunosuppressive factor IDO-1, while they also stimulate proliferation of $\mathrm{T}$ cells and percentage of $\mathrm{CD} 4{ }^{+} \mathrm{CD} 25^{+} \mathrm{FoxP} 3^{+}$cells within [113]. This discrepancy points out how different approaches used in experimental settings can give different results. Interestingly, it has been found that AT-MSCs actually inhibit activation of T cells and stimulate FoxP3 mRNA expression in activated T cells [8].

Some differences exist between bone marrow- and adipose tissue-derived MSCs for several secreted proteins, such as cytokines $($ IFN- $\gamma$ ), growth factors (e.g. fibroblast growth factor (FGF), hepatocyte growth factor (HGF), insulin-like growth factor-1 (IGF-1)), and chemokines (stem cell factor-1 (SCF-1)), where it has been demonstrated that AT-MSCs have more potent immunomodulatory effects than BM-MSCs through higher production of IDO-1 and PGE2 molecules [114]. Also, in co-culture with AT-MSCs, decreased production of proinflammatory cytokines, such as IFN- $\gamma$, IL-2 and IL-17, and increased secretion of anti-inflammatory cytokines, such as TGF- $\beta$, IL-4, IL-10 and IL-13, by stimulated splenocytes have been observed. These immunosuppressive effects of AT-MSCs have crucial effects on maintenance of functionality of pancreatic islets in induced diabetic mice model [115]. Additionally, the immunosuppressive role of AT-MSCs in rheumatoid arthritis, autoimmune disease accompanied by chronic inflammation, has been demonstrated, where AT-MSCs suppress T cell proliferation and increase generation of regulatory subsets of T and B cells [116]. Moreover, it has been shown that AT-MSCs decrease the expression level of CD8 on CD8 ${ }^{+}$cells, and this effect requires direct cell contact of $\mathrm{CD} 14^{+}$monocytes with $\mathrm{CD}^{+}$cells. Finally, AT-MSCs induce the suppressive phenotype of $\mathrm{CD}^{+}$cells and tolerogenic phenotype of $\mathrm{CD} 14^{+}$monocytes, by decreasing expression of CD80 and CD86 co-stimulatory molecules and, on the other hand, increasing the inhibitory receptors immunoglobulin-like transcripts (ILT)-3 and -4 [117].

As has been previously described for BM-MSCs, osteogenic differentiation can maintain hypoimmunogenic profile of AT-MSCs, even though they have been primed with IFN- $\gamma$ and TNF- $\alpha$ [118].

Interesting results have been published after investigating AT-MSCs obtained from fat of obesity patients. Results have showed that AT-MSCs obtained from obesity and non-obesity donors possess similar phenotype, although AT-MSC derived from obesity patients have higher gene expression of inflammatory molecules such as IL-8, IL-1 $\beta$, CCL2 [119,120]. How obesity patient-derived AT-MSCs affect immune response remains to be elucidated.

\section{Immunomodulatory Properties of MSCs in Dental Tissues}

Infection and inflammation have significant effects on the regenerative processes in dental tissues [121]. According to their localization in tooth, dental tissue stem cells, termed as MSCs have been classified as: dental pulp stem cells (DP-MSCs) firstly isolated by Gronthos et al. [122], stem cells from human exfoliated deciduous teeth (SHEDs) [123], periodontal ligament stem cells (PDLSCs) [124,125] stem cells from apical papilla (SCAPs) [126], dental follicle progenitor cells (DFPCs) [127], tooth germ progenitor cells (TGPCs) [128], alveolar bone MSCs (AB-MSCs) [129] and gingival MSCs (GMSCs) [130]. Their application in dental regenerative medicine is dependent of their origin and localization in the tooth, which shape their phenotype and functionality [131-133].

The oral cavity is enriched by commensal bacteria that live in a mutually beneficial state with the host. In dental tissues, stem cells are homed toward infections, inflammation or tissue damage sites, where they come in contact with various bacteria. In inflammatory microenvironment, immune cells such as macrophages and neutrophils are attracted into dental tissue and periapical lesions. Today it is known that stem cells of dental tissue are actively engaged in the control of infections, through direct or indirect effects on host immune response $[132,134]$. Therefore, together with regenerative properties, immunomodulatory activity of dental tissue stem cells has strong impact on the maintenance of healthy dental tissue in physiological conditions as well as in diseases such as periodontitis $[121,135]$.

Human DP-MSCs express Fas ligand and are able to provoke apoptosis of T cells and this activity was followed by decreased number of Th17 cells and increased number of Treg cells. It has been shown that these effects are mediated by expression of TGF- $\beta$, HGF and IDO- 1 in DP-MSCs $[9,130,133,135]$. Also, it has been demonstrated that SHEDs effectively inhibit proliferation of already activated $\mathrm{T}$ cells by inducing their apoptosis and moreover inducing generation of Treg, in similar manner as BMMSCs, yet with a stronger effect [136]. Furthermore, it has been observed that SHEDs induce an immune regulatory phenotype in monocyte-derived DCs cells [137]. PDL-MSC have also been shown to possess immunosuppressive capacity [138], inhibiting proliferation of peripheral blood mononuclear cells, by producing TGF- $\beta$, HFG, IDO-1 and PGE2 molecules [135]. However, it has been demonstrated that PDL-MSCs isolated from inflamed periodontal ligament inhibit proliferation of T cells significantly less than PDL-MSCs isolated from healthy donors. These effects are accompanied by lower generation of Treg and higher differentiation of Th17 cells, induced by PDL-MSCs [139].

Also, an inhibitory role of PDL-MSCs on B cell activation has been reported, where it has been observed that these MSCs regulate innate immune response through the expression of program cell death-1 (PDL-1) [140]. Similarly, G-MSCs show immunosuppressive effects through inhibition of $\mathrm{T}$ cell proliferation, mediated by IDO, IL-10, and cyclooxygenase-2 (COX-2) [135]. DFPCs also inhibit proliferation of peripheral blood mononuclear cells, due to increased expression of TGF- $\beta$, mediated by activation of inhibitory molecules TLR3 and TLR4 [141]. There are some indications in immunomodulatory activity of SCAPs [142], but mechanisms of their immunosuppressive properties are not clarified yet.

Annex Publishers | www.annexpublishers.com 
G-MSCs inhibit proliferation of T-cell proliferation via expression of IDO, IL-10, COX-2, and iNOS, while increasing generation of Treg cells $[143,144]$ and polarizing macrophages toward anti-inflammatory M2 phenotype [145]. There is no data about the immunomodulatory activity of AB-MSCs and TGPCs. Also, at this moment there is no evidence about immunogenicity of MSCs derived from dental tissues.

\section{Conclusion}

As regenerative medicine requires alternative sources of MSCs, various tissues are being investigated with the aim to substitute bone marrow as the firstly proposed source of MSCs. However, although immune status and activity of MSCs isolated from some tissues such as adipose and fetal tissues are being intensively investigated, there are many obstacles for their potential clinical application. MSCs must be examined in the context of their native tissue microenvironment which shapes their immune activity in accordance with maintenance of tissue homeostasis. Therefore, tissue resident MSCs might possess specific native immune profiles, which are further on reflected during their in vitro or ex vivo expansion, and therefore must be considered before potential use in clinical settings.

\section{Acknowledgement}

This study was supported by grant \#175062 from the Ministry of Education, Science and Technological Development of Republic of Serbia.

\section{References}

1. Caplan AI (2007) Adult mesenchymal stem cells for tissue engineering versus regenerative medicine. J Cell Physiol 213: 341-7.

2. Dominici M, Le Blanc K, Mueller I, Slaper-Cortenbach I, Marini F, et al. (2006) Minimal criteria for defining multipotent mesenchymal stromal cells. The International Society for Cellular Therapy position statement. Cytotherapy 8: 315-7.

3. Prockop DJ, Prockop SE, Bertoncello I (2014) Are clinical trials with mesenchymal stem/progenitor cells too far ahead of the science? Lessons from experimental hematology. Stem Cells 32: 3055-61.

4. Caplan AI, Sorrell JM (2015) The MSC curtain that stops the immune system. Immunol Lett 168: 136-9.

5. Keating A (2012) Mesenchymal stromal cells: new directions. Cell Stem Cell 10: 709-16.

6. Pacini S (2014) Deterministic and stochastic approaches in the clinical application of mesenchymal stromal cells (MSCs). Front Cell Dev Biol 2: 50.

7. Samsonraj RM, Rai B, Sathiyanathan P, Puan KJ, Rötzschke O, et al. (2015) Establishing criteria for human mesenchymal stem cell potency. Stem Cells 33: 187891.

8. Ribeiro A, Laranjeira P, Mendes S, Velada I, Leite C, et al. (2013) Mesenchymal stem cells from umbilical cord matrix, adipose tissue and bone marrow exhibit different capability to suppress peripheral blood B, natural killer and T cells. Stem Cell Res Ther 4: 125.

9. Trivanović D, Mojsilović S, Ilić V, Krstić J, Jauković A, et al. (2013) Immunomodulatory capacity of human mesenchymal stem cells isolated from adipose tissue, dental pulp, peripheral blood and umbilical cord Wharton's jelly. Centr Eur J Immunol 38: 421-9.

10. Lazarus HM, Haynesworth SE, Gerson SL, Rosenthal NS, Caplan AI (1995) Ex vivo expansion and subsequent infusion of human bone marrow-derived stromal progenitor cells (mesenchymal progenitor cells): implications for therapeutic use. Bone Marrow Transplant 16: 557-64.

11. Grinnemo KH, Månsson A, Dellgren G, Klingberg D, Wardell E, et al. (2004) Xenoreactivity and engraftment of human mesenchymal stem cells transplanted into infarcted rat myocardium. J Thorac Cardiovasc Surg 127: 1293-300.

12. Fiorina P, Jurewicz M, Augello A, Vergani A, Dada S, et al. (2009) Immunomodulatory function of bone marrow-derived mesenchymal stem cells in experimental autoimmune type 1 diabetes. J Immunol 183: 993-1004.

13. Eliopoulos N, Stagg J, Lejeune L, Pommey S, Galipeau J (2005) Allogeneic marrow stromal cells are immune rejected by MHC class I- and class II-mismatched recipient mice. Blood 106: 4057-65.

14. Rasmusson I, Le Blanc K, Sundberg B, Ringdén O (2007) Mesenchymal stem cells stimulate antibody secretion in human B cells. Scand J Immunol 65: 336-43.

15. Shi Y Cao J, Wang Y (2015) Rethinking regeneration: empowerment of stem cells by inflammation. Cell Death Differ 22: 1891-2.

16. Caplan AI (2015) Adult Mesenchymal Stem Cells: When, Where, and How. Stem Cells Int 10.1155/2015/628767.

17. Pevsner-Fischer M, Levin S, Zipori D (2011) The origins of mesenchymal stromal cell heterogeneity. Stem Cell Rev 7: 560-8.

18. Gao F, Chiu SM, Motan DA, Zhang Z, Chen L, et al. (2016) Mesenchymal stem cells and immunomodulation: current status and future prospects. Cell Death Dis 7: 10.1038/cddis.2015.327.

19. Friedenstein AJ, Petrakova KV, Kurolesova AI, Frolova GP (1968) Heterotopic of bone marrow. Analysis of precursor cells for osteogenic and hematopoietictissues. Transplantation 6: 230-47.

20. Friedenstein AJ, Chailakhyan RK, Gerasimov UV (1987) Bone marrow osteogenic stem cells: in vitro cultivation and transplantation in diffusion chambers. Cell Tissue Kinet 20: 263-72.

21. Owen M, Friedenstein AJ (1988) Stromal stem cells: marrow-derived osteogenic precursors. Ciba Found Symp 136: 42-60.

22. Le Blanc K, Ringdén O (2005) Immunobiology of human mesenchymal stem cells and future use in hematopoietic stem cell transplantation. Biol Blood Marrow Transplant 11: 321-34.

23. Morrison SJ, Scadden DT (2014) The bone marrow niche for haematopoietic stem cells. Nature 505: 327-34.

24. Aggarwal S, Pittenger MF (2005) Human mesenchymal stem cells modulate allogeneic immune cell responses. Blood 105: 1815-22.

25. Nombela-Arrieta C, Ritz J, Silberstein LE (2011) The elusive nature and function of mesenchymal stem cells. Nat Rev Mol Cell Biol 12: 126-31.

26. Freeman BT, Jung JP, Ogle BM (2015) Single-Cell RNA-Seq of Bone Marrow-Derived Mesenchymal Stem Cells Reveals Unique Profiles of Lineage Priming. PLoS One 10: 10.1371/journal.pone.0136199. 
27. Phinney DG (2012) Functional heterogeneity of mesenchymal stem cells: implications for cell therapy. J Cell Biochem 113: $2806-12$.

28. Whitfield MJ, Lee WC, Van Vliet KJ (2013) Onset of heterogeneity in culture-expanded bone marrow stromal cells. Stem Cell Res 11: $1365-77$.

29. Bara JJ, Richards RG, Alini M, Stoddart MJ (2014) Concise review: Bone marrow-derived mesenchymal stem cells change phenotype following in vitro culture: Implications for basic research and the clinic. Stem Cells 32: 1713-23.

30. Bartosh TJ, Ylöstalo JH, Bazhanov N, Kuhlman J, Prockop DJ (2013) Dynamic compaction of human mesenchymal stem/precursor cells into spheres selfactivates caspase-dependent IL1 signaling to enhance secretion of modulators of inflammation and immunity (PGE2, TSG6, and STC1). Stem Cells 31: 2443-56.

31. Feng J, Mantesso A, De Bari C, Nishiyama A, Sharpe PT (2011) Dual origin of mesenchymal stem cells contributing to organ growth and repair. Proc Natl Acad Sci U S A 108: 6503-8.

32. Murray IR, Péault B (2015) Q\&A: Mesenchymal stem cells - where do they come from and is it important? BMC Biol 13: 99.

33. Griffin MD, Ryan AE, Alagesan S, Lohan P, Treacy O, et al. (2013) Anti-donor immune responses elicited by allogeneic mesenchymal stem cells: what have we learned so far? Immunol Cell Biol 91: 40-51.

34. Ball LM, Bernardo ME, Roelofs H, van Tol MJ, Contoli B, et al. (2013) Multiple infusions of mesenchymal stromal cells induce sustained remission in children with steroid-refractory, grade III-IV acute graft-versus-host disease. Br J Haematol 163: 501-9.

35. Jiang S, Xia M, Yang J, Shao J, Liao X, et al. (2015) Novel insights into a treatment for aplastic anemia based on the advanced proliferation of bone marrow derived mesenchymal stem cells induced by fibroblast growth factor 1. Mol Med Rep 12: 7877-82.

36. Ciccocioppo R, Cangemi GC, Kruzliak P, Gallia A, Betti E, et al. (2015) Ex vivo immunosuppressive effects of mesenchymal stem cells on Crohn's disease mucosal T cells are largely dependent on indoleamine 2,3-dioxygenase activity and cell-cell contact. Stem Cell Res Ther 6: 137.

37. El-Akabawy G, Rashed LA (2015) Beneficial effects of bone marrow-derived mesenchymal stem cell transplantation in a non-immune model of demyelination. Ann Anat 198: 11-20.

38. Mathiasen AB, Qayyum AA, Jørgensen E, Helqvist S, Fischer-Nielsen A, et al. (2015) Bone marrow-derived mesenchymal stromal cell treatment in patients with severe ischaemic heart failure: a randomized placebo-controlled trial (MSC-HF trial). Eur Heart J 36: $1744-53$.

39. Le Blanc K, Rasmusson I, Sundberg B, Götherström C, Hassan M, et al. (2004) Treatment of severe acute graft-versus-host disease with third party haploidentical mesenchymal stem cells. Lancet 363: 1439-41.

40. Ankrum JA, Ong JF, Karp JM (2014) Mesenchymal stem cells: immune evasive, not immune privileged. Nat Biotechnol 32: 252-60.

41. Dos Santos F, Campbell A, Fernandes-Platzgummer A, Andrade PZ, Gimble JM, et al. (2014) A xenogeneic-free bioreactor system for the clinical-scale expansion of human mesenchymal stem/stromal cells. Biotechnol Bioeng 111: 1116-27.

42. Wang Y, Chen X, Cao W, Shi Y (2014) Plasticity of mesenchymal stem cells in immunomodulation: pathological and therapeutic implications. Nat Immunol 15: 1009-16.

43. Bunnell BA, Betancourt AM, Sullivan DE (2010) New concepts on the immune modulation mediated by mesenchymal stem cells. Stem Cell Res Ther 1: 34.

44. Liu WH, Liu JJ, Wu J, Zhang LL, Liu F, et al. (2013) Novel mechanism of inhibition of dendritic cells maturation by mesenchymal stem cells via interleukin-10 and the JAK1/STAT3 signaling pathway. PLoS One 8: e55487.

45. Luz-Crawford P, Djouad F, Toupet K, Bony C, Franquesa M, et al. (2015) Mesenchymal stem cell-derived IL1RA promotes macrophage polarization and inhibits B cell differentiation. Stem Cells 10.1002/stem.2254.

46. Jang IK, Yoon HH, Yang MS, Lee JE, Lee DH, et al. (2014) B7-H1 inhibits T cell proliferation through MHC class II in human mesenchymal stem cells. Transplant Proc 46: 1638-41.

47. Luz-Crawford P, Kurte M, Bravo-Alegría J, Contreras R, Nova-Lamperti E, et al. (2013) Mesenchymal stem cells generate a CD4+CD25+Foxp3+ regulatory T cell population during the differentiation process of Th1 and Th17 cells. Stem Cell Res Ther 4: 65.

48. Spaggiari GM, Capobianco A, Abdelrazik H, Becchetti F, Mingari MC, et al. (2008) Mesenchymal stem cells inhibit natural killer-cell proliferation, cytotoxicity, and cytokine production: role of indoleamine 2,3-dioxygenase and prostaglandin E2. Blood 111: 1327-33.

49. L. Dolcetti, F. Dazzi (2015) Therapeutic Immunomodulation with Mesenchymal Stromal Cells: The Need for In vivo Clues. Int J Transla Sci 1: 10.13052/ijts22468765.2015.003.

50. Chen HW, Chen HY, Wang LT, Wang FH, Fang LW, et al. (2013) Mesenchymal stem cells tune the development of monocyte-derived dendritic cells toward a myeloid-derived suppressive phenotype through growth-regulated oncogene chemokines. J Immunol 190: 5065-77.

51. Waterman RS, Tomchuck SL, Henkle SL, Betancourt AM (2010) A new mesenchymal stem cell (MSC) paradigm: polarization into a pro-inflammatory MSC1 or an Immunosuppressive MSC2 phenotype. PLoS One 5: e10088.

52. Nauta AJ, Westerhuis G, Kruisselbrink AB, Lurvink EG, Willemze R, et al. (2006) Donor-derived mesenchymal stem cells are immunogenic in an allogeneic host and stimulate donor graft rejection in a nonmyeloablative setting. Blood 108: 2114-20.

53. Gu LH, Zhang TT, Li Y, Yan HJ, Qi H, et al. (2015) Immunogenicity of allogeneic mesenchymal stem cells transplanted via different routes in diabetic rats. Cell Mol Immunol 12: 444-55.

54. Mukonoweshuro B, Brown CJ, Fisher J, Ingham E (2014) Immunogenicity of undifferentiated and differentiated allogeneic mouse mesenchymal stem cells. J Tissue Eng 5: 10.1177/2041731414534255.

55. Mattar P, Bieback K (2015) Comparing the Immunomodulatory Properties of Bone Marrow, Adipose Tissue, and Birth-Associated Tissue Mesenchymal Stromal Cells. Front Immunol 6: 560.

56. Hoogduijn MJ (2015) Are mesenchymal stromal cells immune cells? Arthritis Res Ther 17: 88.

57. Roemeling-van Rhijn M, Reinders ME, Franquesa M, Engela AU, Korevaar SS, et al. (2013) Human Allogeneic Bone Marrow and Adipose Tissue Derived Mesenchymal Stromal Cells Induce CD8+ Cytotoxic T Cell Reactivity. J Stem Cell Res Ther 3: 004.

58. Thomas H, Jäger M, Mauel K, Brandau S, Lask S, et al. (2014) Interaction with mesenchymal stem cells provokes natural killer cells for enhanced IL-12/IL18-induced interferon-gamma secretion. Mediators Inflamm 10.1155/2014/143463.

59. Traggiai E, Volpi S, Schena F, Gattorno M, Ferlito F, et al. (2008) Bone marrow-derived mesenchymal stem cells induce both polyclonal expansion and differentiation of B cells isolated from healthy donors and systemic lupus erythematosus patients. Stem Cells 26: 562-9.

60. Che N, Li X, Zhang L, Liu R, Chen H, et al. (2014) Impaired B cell inhibition by lupus bone marrow mesenchymal stem cells is caused by reduced CCL2 expression. J Immunol 193: 5306-14. 
61. Moll G, Rasmusson-Duprez I, von Bahr L, Connolly-Andersen AM, Elgue G, et al. (2012) Are therapeutic human mesenchymal stromal cells compatible with human blood? Stem Cells 30: 1565-74.

62. Seifert M, Stolk M, Polenz D, Volk HD (2012) Detrimental effects of rat mesenchymal stromal cell pre-treatment in a model of acute kidney rejection. Front Immunol 3: 202.

63. Alagesan S, Griffin MD (2014) Autologous and allogeneic mesenchymal stem cells in organ transplantation: what do we know about their safety and efficacy? Curr Opin Organ Transplant 19: 65-72.

64. Rafei M, Birman E, Forner K, Galipeau J (2009) Allogeneic mesenchymal stem cells for treatment of experimental autoimmune encephalomyelitis. Mol Ther 17: 1799-803.

65. Lohan P, Coleman CM, Murphy JM, Griffin MD, Ritter T, et al. (2014) Changes in immunological profile of allogeneic mesenchymal stem cells after differentiation: should we be concerned? Stem Cell Res Ther 5: 99.

66. Le Blanc K, Tammik C, Rosendahl K, Zetterberg E, Ringdén O (2003) HLA expression and immunologic properties of differentiated and undifferentiated mesenchymal stem cells. Exp Hematol 31: 890-6.

67. Ryan AE, Lohan P, O’Flynn L, Treacy O, Chen X, et al. (2014) Chondrogenic differentiation increases antidonor immune response to allogeneic mesenchymal stem cell transplantation. Mol Ther 22: 655-67.

68. Haque N, Kasim NH, Rahman MT (2015) Optimization of pre-transplantation conditions to enhance the efficacy of mesenchymal stem cells. Int J Biol Sci 11: 324-34.

69. Ma S, Xie N, Li W, Yuan B, Shi Y, et al. (2013) Immunobiology of mesenchymal stem cells. Cell Death Differ 21: $216-25$.

70. Villaron EM, Almeida J, López-Holgado N, Alcoceba M, Sánchez-Abarca LI, et al. (2004) Mesenchymal stem cells are present in peripheral blood and can engraft after allogeneic hematopoietic stem cell transplantation. Haematologica 89: 1421-7.

71. Wexler SA, Donaldson C, Denning-Kendall P, Rice C, Bradley B, et al. (2003) Adult bone marrow is a rich source of human mesenchymal 'stem' cells but umbilical cord and mobilized adult blood are not. Br J Haematol 121: 368-74.

72. Kassis I, Zangi L, Rivkin R, Levdansky L, Samuel S, et al. (2006) Isolation of mesenchymal stem cells from G-CSF-mobilized human peripheral blood using fibrin microbeads. Bone Marrow Transplant 37: 967-76.

73. Trivanović D, Kocić J, Mojsilović S, Krstić A, Ilić V, et al. (2013) Mesenchymal stem cells isolated from peripheral blood and umbilical cord Wharton’s jelly. Srp Arh Celok Lek 141: 178-86.

74. Krstić J, Obradović H, Jauković A, Okić-Đorđević I, Trivanović D, et al. (2015) Urokinase type plasminogen activator mediates Interleukin-17-induced peripheral blood mesenchymal stem cell motility and transendothelial migration. Biochim Biophys Acta 1853: 431-44.

75. Ljujic B, Milovanovic M, Volarevic V, Murray B, Bugarski D, et al. (2013) Human mesenchymal stem cells creating an immunosuppressive environment and promote breast cancer in mice. Sci Rep 3: 10.1038/srep02298.

76. Li S, Huang KJ, Wu JC, Hu MS, Sanyal M, et al. (2015) Peripheral blood-derived mesenchymal stem cells: candidate cells responsible for healing critical-sized calvarial bone defects. Stem Cells Transl Med 4: 359-68.

77. Chan RW, Schwab KE, Gargett CE (2004) Clonogenicity of human endometrial epithelial and stromal cells. Biol Reprod 70: 1738-50.

78. Meng X, Ichim TE, Zhong J, Rogers A, Yin Z, et al. (2007) Endometrial regenerative cells: a novel stem cell population. J Transl Med 5: 57.

79. Gargett CE, Schwab KE, Deane JA (2015) Endometrial stem/progenitor cells: the first 10 years. Hum Reprod Update 10.1093/humupd/dmv051.

80. Khoury M, Alcayaga-Miranda F, Illanes SE, Figueroa FE (2014) The promising potential of menstrual stem cells for antenatal diagnosis and cell therapy. Front Immunol 5: 205.

81. Alcayaga-Miranda F, Cuenca J, Luz-Crawford P, Aguila-Díaz C, Fernandez A, et al. (2015) Characterization of menstrual stem cells: angiogenic effect, migration and hematopoietic stem cell support in comparison with bone marrow mesenchymal stem cells. Stem Cell Res Ther 6: 32.

82. Luz-Crawford P, Torres MJ, Noël D, Fernandez A, Toupet K, et al. (2015) The Immunosuppressive Signature of Menstrual Blood Mesenchymal Stem Cells Entails Opposite Effects on Experimental Arthritis and Graft Versus Host Diseases. Stem Cells 10.1002/stem.2244.

83. Bozorgmehr M, Moazzeni SM, Salehnia M, Sheikhian A, Nikoo S, et al. (2014) Menstrual blood-derived stromal stem cells inhibit optimal generation and maturation of human monocyte-derived dendritic cells. Immunol Lett 162: 239-46.

84. Kim DW, Staples M, Shinozuka K, Pantcheva P, Kang SD, et al. (2013) Wharton's jelly-derived mesenchymal stem cells: phenotypic characterization and optimizing their therapeutic potential for clinical applications. Int J Mol Sci 14: 11692-712.

85. Ishii T, Eto K (2014) Fetal stem cell transplantation: Past, present, and future. World J Stem Cells 6: 404-20.

86. Steigman SA, Fauza DO (2007) Isolation of mesenchymal stem cells from amniotic fluid and placenta. Curr Protoc Stem Cell Biol 1: 10.1002/9780470151808. sc01e02s1.

87. Tamagawa T, Oi S, Ishiwata I, Ishikawa H, Nakamura Y (2007) Differentiation of mesenchymal cells derived from human amniotic membranes into hepatocytelike cells in vitro. Hum Cell 20: 77-84.

88. Macias MI, Grande J, Moreno A, Domínguez I, Bornstein R, et al. (2010) Isolation and characterization of true mesenchymal stem cells derived from human term decidua capable of multilineage differentiation into all 3 embryonic layers. Am J Obstet Gynecol 203: 10.1016/j.ajog.2010.06.045.

89. Portmann-Lanz CB, Schoeberlein A, Huber A, Sager R, Malek A, et al. (2006) Placental mesenchymal stem cells as potential autologous graft for pre- and perinatal neuroregeneration. Am J Obstet Gynecol 194: 664-73.

90. McNiece IK, Almeida-Porada G, Shpall EJ, Zanjani E (2002) Ex vivo expanded cord blood cells provide rapid engraftment in fetal sheep but lack long-term engrafting potential. Exp Hematol 30: 612-6.

91. Majore I, Moretti P, Stahl F, Hass R, Kasper C (2011) Growth and differentiation properties of mesenchymal stromal cell populations derived from whole human umbilical cord. Stem Cell Rev 7: 17-31.

92. Hass R, Kasper C, Böhm S, Jacobs R (2011) Different populations and sources of human mesenchymal stem cells (MSC): A comparison of adult and neonatal tissue-derived MSC. Cell Commun Signal 9: 12.

93. Burt TD (2013) Fetal regulatory T cells and peripheral immune tolerance in utero: implications for development and disease. Am J Reprod Immunol 69: 346-58.

94. Nagamura-Inoue T, He H (2014) Umbilical cord-derived mesenchymal stem cells: Their advantages and potential clinical utility. World J Stem Cells 6: 195-202. 
95. Bárcia RN, Santos JM, Filipe M, Teixeira M, Martins JP, et al. (2015) What Makes Umbilical Cord Tissue-Derived Mesenchymal Stromal Cells Superior Immunomodulators When Compared to Bone Marrow Derived Mesenchymal Stromal Cells? Stem Cells Int 2015 : 583984.

96. Chen H, Zhang N, Li T, Guo J, Wang Z, et al. (2012) Human umbilical cord Wharton's jelly stem cells: immune property genes assay and effect of transplantation on the immune cells of heart failure patients. Cell Immunol 276: 83-90.

97. Fu L, Liu Y, Zhang D, Xie J, Guan H, et al. (2015) Beneficial effect of human umbilical cord-derived mesenchymal stem cells on an endotoxin-induced rat model of preeclampsia. Exp Ther Med 10: 1851-6.

98. Kalaszczynska I, Ferdyn K (2015) Wharton's jelly derived mesenchymal stem cells: future of regenerative medicine? Recent findings and clinical significance. Biomed Res Int 10.1155/2015/430847.

99. Yoo KH, Jang IK, Lee MW, Kim HE, Yang MS, et al. (2009) Comparison of immunomodulatory properties of mesenchymal stem cells derived from adult human tissues. Cell Immunol 259: 150-6.

100. Najar M, Raicevic G, Boufker HI, Fayyad Kazan H, De Bruyn C, et al. (2010) Mesenchymal stromal cells use PGE2 to modulate activation and proliferation of lymphocyte subsets: Combined comparison of adipose tissue, Wharton's Jelly and bone marrow sources. Cell Immunol 264: 171-9.

101. Castro-Manrreza ME, Mayani H, Monroy-García A, Flores-Figueroa E, Chávez-Rueda K, et al. (2014) Human mesenchymal stromal cells from adult and neonatal sources: a comparative in vitro analysis of their immunosuppressive properties against T cells. Stem Cells Dev 23: 1217-32.

102. Cheng H-Y, Ghetu N, Wallace CG, Wei F-C, Liao S-K (2014) The Impact of Mesenchymal Stem Cell Source on Proliferation, Differentiation, Immunomodulation and Therapeutic Efficacy. J Stem Cell Res Ther 4: 10.4172/2157-7633.1000237.

103. Yen BL, Yen ML, Hsu PJ, Liu KJ, Wang CJ, et al. (2013) Multipotent human mesenchymal stromal cells mediate expansion of myeloid-derived suppressor cells via hepatocyte growth factor/c-met and STAT3. Stem Cell Reports 1: 139-51.

104. Coulson-Thomas VJ, Gesteira TF, Hascall V, Kao W (2014) Umbilical cord mesenchymal stem cells suppress host rejection: the role of the glycocalyx. J Biol Chem 289: 23465-81.

105. Zuk PA, Zhu M, Mizuno H, Huang J, Futrell JW, et al. (2001) Multilineage cells from human adipose tissue: implications for cell-based therapies. Tissue Eng 7: 211-28.

106. Nakao N, Nakayama T, Yahata T, Muguruma Y, Saito S, et al. (2010) Adipose tissue-derived mesenchymal stem cells facilitate hematopoiesis in vitro and in vivo: advantages over bone marrow-derived mesenchymal stem cells. Am J Pathol 177: 547-54.

107. Eto H, Ishimine H, Kinoshita K, Watanabe-Susaki K, Kato H, et al. (2013) Characterization of human adipose tissue-resident hematopoietic cell populations reveals a novel macrophage subpopulation with CD34 expression and mesenchymal multipotency. Stem Cells Dev 22: 985-97.

108. Baptista LS, Silva KR, Borojevic R (2015) Obesity and weight loss could alter the properties of adipose stem cells? World J Stem Cells 7: 165-73.

109. Poglio S, De Toni-Costes F, Arnaud E, Laharrague P, Espinosa E, et al. (2010) Adipose tissue as a dedicated reservoir of functional mast cell progenitors. Stem Cells 28: 2065-72.

110. Miñana MD, Carbonell-Uberos F, Mirabet V, Marín S, Encabo A (2008) IFATS collection: Identification of hemangioblasts in the adult human adipose tissue. Stem Cells 26: 2696-704.

111. Yañez R, Lamana ML, García-Castro J, Colmenero I, Ramírez M, et al. (2006) Adipose tissue-derived mesenchymal stem cells have in vivo immunosuppressive properties applicable for the control of the graft-versus-host disease. Stem Cells 24: 2582-91.

112. Melief SM, Zwaginga JJ, Fibbe WE, Roelofs H (2013) Adipose tissue-derived multipotent stromal cells have a higher immunomodulatory capacity than their bone marrow-derived counterparts. Stem Cells Transl Med 2: 455-63.

113. Crop MJ, Baan CC, Korevaar SS, Ijzermans JN, Weimar W, et al. (2010) Human adipose tissue-derived mesenchymal stem cells induce explosive T-cell proliferation. Stem Cells Dev 19: 1843-53.

114. Li CY, Wu XY, Tong JB, Yang XX, Zhao JL, et al. (2015) Comparative analysis of human mesenchymal stem cells from bone marrow and adipose tissue under xeno-free conditions for cell therapy. Stem Cell Res Ther 6: 55.

115. Rahavi H, Hashemi SM, Soleimani M, Mohammadi J, Tajik N (2015) Adipose tissue-derived mesenchymal stem cells exert in vitro immunomodulatory and beta cell protective functions in streptozotocin-induced diabetic mice model. J Diabetes Res 10.1155/2015/878535.

116. Garimella MG, Kour S, Piprode V, Mittal M, Kumar A, et al. (2015) Adipose-Derived Mesenchymal Stem Cells Prevent Systemic Bone Loss in CollagenInduced Arthritis. J Immunol 195: 5136-48.

117. Hof-Nahor I, Leshansky L, Shivtiel S, Eldor L, Aberdam D, et al. (2012) Human mesenchymal stem cells shift CD8+ T cells towards a suppressive phenotype by inducing tolerogenic monocytes. J Cell Sci 125: 4640-50.

118. Montespan F, Deschaseaux F, Sensébé L, Carosella ED, Rouas-Freiss N (2014) Osteodifferentiated mesenchymal stem cells from bone marrow and adipose tissue express HLA-G and display immunomodulatory properties in HLA-mismatched settings: implications in bone repair therapy. J Immunol Res 10.1155/2014/230346.

119. Oñate B, Vilahur G, Camino-López S, Díez-Caballero A, Ballesta-López C, et al. (2013) Stem cells isolated from adipose tissue of obese patients show changes in their transcriptomic profile that indicate loss in stemcellness and increased commitment to an adipocyte-like phenotype. BMC Genomics 14: 625.

120. Pérez LM, Bernal A, San Martín N, Lorenzo M, Fernández-Veledo S, et al. (2013) Metabolic rescue of obese adipose-derived stem cells by Lin28/Let7 pathway. Diabetes 62: 2368-79.

121. Cooper PR, Smith AJ (2013) Molecular mediators of pulp inflammation and regeneration. Endodontic Topics 28: 90-105.

122. Gronthos S, Mankani M, Brahim J, Robey PG, Shi S (2000) Postnatal human dental pulp stem cells (DPSCs) in vitro and in vivo. Proc Natl Acad Sci U S A 97: $13625-30$.

123. Miura M, Gronthos S, Zhao M, Lu B, Fisher LW, et al. (2003) SHED: stem cells from human exfoliated deciduous teeth. Proc Natl Acad Sci U S A 100: 5807-12. 124. Kramer PR, Nares S, Kramer SF, Grogan D, Kaiser M (2004) Mesenchymal stem cells acquire characteristics of cells in the periodontal ligament in vitro. J Dent Res 83: 27-34.

125. Miletić M, Mojsilović S, Okić-Djordjević I, Kukolj T, Jauković A, et al. (2014) Mesenchymal stem cells isolated from human periodontal ligament. Arch Biol Sci 66: 261-71.

126. Sonoyama W, Liu Y, Yamaza T, Tuan RS, Wang S, et al. (2008) Characterization of the apical papilla and its residing stem cells from human immature permanent teeth: a pilot study. J Endod 34: 166-71. 
127. Yao S, Pan F, Prpic V, Wise GE (2008) Differentiation of stem cells in the dental follicle. J Dent Res 87: 767-71.

128. Ikeda E, Yagi K, Kojima M, Yagyuu T, Ohshima A, et al. (2007) Multipotent cells from the human third molar: feasibility of cell-based therapy for liver disease. Differentiation 76: 495-505.

129. Mason S, Tarle SA, Osibin W, Kinfu Y, Kaigler D (2014) Standardization and safety of alveolar bone-derived stem cell isolation. J Dent Res 93: 55-61.

130. Liu J, Yu F, Sun Y, Jiang B, Zhang W, et al. (2015) Concise reviews: Characteristics and potential applications of human dental tissue-derived mesenchymal stem cells. Stem Cells 33: 627-38.

131. Park Y-J, Cha S, Park Y-S (2015) Regenerative Applications Using Tooth Derived Stem Cells in Other Than Tooth Regeneration: A Literature Review. Stem Cells Int Article 10.1155/2016/9305986.

132. Leprince JG, Zeitlin BD, Tolar M, Peters OA (2012) Interactions between immune system and mesenchymal stem cells in dental pulp and periapical tissues. Int Endod J 45: 689-701.

133. Sonoda S, Tomoda E, Tanaka Y, Yamaza T (2015) Properties and Possibilities of Human Dental Pulp-Derived Stem Cells. Arch Stem Cell Res 2: 1012.

134. Chatzivasileiou K, Kriebel K, Steinhoff G, Kreikemeyer B, Lang H (2015) Do oral bacteria alter the regenerative potential of stem cells? A concise review. J Cell Mol Med 19: 2067-74.

135. Racz GZ, Kadar K, Foldes A, Kallo K, Perczel-Kovach K, et al. (2014) Immunomodulatory and potential therapeutic role of mesenchymal stem cells in periodontitis. J Physiol Pharmacol 65: 327-39.

136. Yamaza T, Kentaro A, Chen C, Liu Y, Shi Y, et al. (2010) Immunomodulatory properties of stem cells from human exfoliated deciduous teeth. Stem Cell Res Ther 1: 5 .

137. Silva Fde S, Ramos RN, de Almeida DC, Bassi EJ, Gonzales RP, et al. (2014) Mesenchymal Stem Cells Derived from Human Exfoliated Deciduous Teeth (SHEDs) Induce Immune Modulatory Profile in Monocyte-Derived Dendritic Cells. PLoS ONE 9: e98050.

138. Wada N, Menicanin D, Shi S, Bartold PM, Gronthos S (2009) Immunomodulatory properties of human periodontal ligament stem cells. J Cell Physiol 219: $667-76$.

139. Liu D, Xu J, Liu O, Fan Z, Liu Y, et al. (2012) Mesenchymal stem cells derived from inflamed periodontal ligaments exhibit impaired immunomodulation. J Clin Periodontol 39: 1174-82.

140. Liu O, Xu J, Ding G, Liu D, Fan Z, et al. (2013) Periodontal ligament stem cells regulate B lymphocyte function via programmed cell death protein 1. Stem Cells 31: 1371-82.

141. Tomic S, Djokic J, Vasilijic S, Vucevic D, Todorovic V, et al. (2011) Immunomodulatory properties of mesenchymal stem cells derived from dental pulp and dental follicle are susceptible to activation by toll-like receptor agonists. Stem Cells Dev 20: 695-708.

142. Ding G, Wang W, Liu Y, An Y, Zhang C, et al. (2010) Effect of cryopreservation on biological and immunological properties of stem cells from apical papilla. J Cell Physiol 223: 415-22.

143. Zhang Q, Shi S, Liu Y, Uyanne J, Shi Y, et al. (2009) Mesenchymal stem cells derived from human gingiva are capable of immunomodulatory functions and ameliorate inflammation-related tissue destruction in experimental colitis. J Immunol 183: 7787-98.

144. Chen M, Su W, Lin X, Guo Z, Wang J, et al. (2013) Adoptive transfer of human gingiva-derived mesenchymal stem cells ameliorates collagen-induced arthritis via suppression of Th1 and Th17 cells and enhancement of regulatory T cell differentiation. Arthritis Rheum 65: 1181-93.

145. Zhang QZ, Su WR, Shi SH, Wilder-Smith P, Xiang AP, et al. (2010) Human gingiva-derived mesenchymal stem cells elicit polarization of 2 macrophages and enhance cutaneous wound healing. Stem Cells 28: 1856-68.

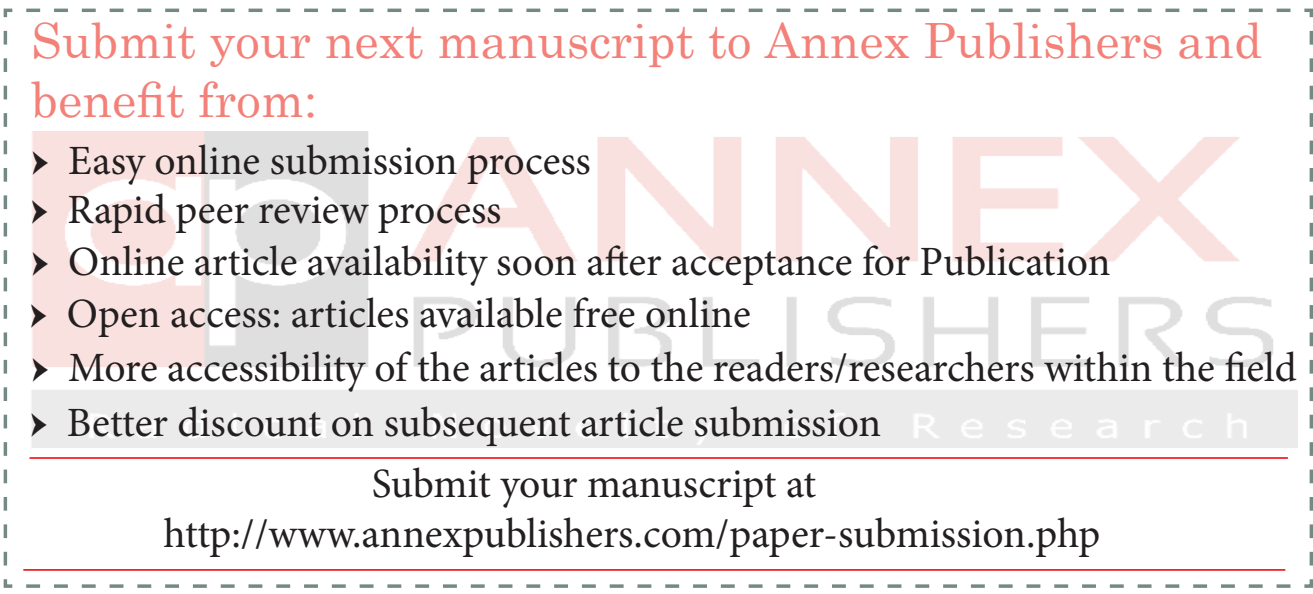

